\title{
João Cabral de Melo Neto e a tradição do Romance de 30 RICARDO SOUZA DE CARVALHO
}

\section{Da poesia à prosa}

Q

UANDO João Cabral de Melo Neto começou a escrever poesia no Recife do final dos anos 1930, perdia fôlego a vigorosa produção de romances de autores nordestinos que caracterizou um momento decisivo da literatura orasileira: Rachel de Queiroz, depois de O quinze (1930) e mais três romances, ${ }^{1}$ passaria a se dedicar ao jornalismo; José Lins do Rego já criara o seu "ciclo da cana-de-açúcar", ${ }^{2}$ antes de chegar à obra-prima Fogo morto (1943); e Graciliano Ramos encerrara com Vidas secas (1938) a sua série de "ficções" para explorar a "confissão" das memórias. O grupo que Cabral frequentava, liderado por Willy Lewin, preferia cultivar uma poesia inspirada pelas sugestões do sonho, em lugar dos estímulos da terra que provocaram poetas da região durante a década de 1920, como Jorge de Lima, Ascenso Ferreira, Joaquim Cardozo e Jorge Fernandes. Não era mais tempo do Primeiro Congresso Regionalista do Nordeste, no qual, em 1926, Gilberto Freyre lançara seu célebre manifesto de valorização de temas regionais, mas sim do Congresso de Poesia do Recife, no qual, em 1941, Cabral apresentaria sua tese "Considerações sobre o poeta dormindo".

Embora a obra de estreia Pedra do sono (1942) muito deva a esse contexto inicial, nada regionalista, Cabral desde cedo se tornou leitor dos romancistas nordestinos da década anterior. Mas seu caminho rumo a uma poesia cada vez mais centrada em seu aspecto construtivo, culminando em Psicologia da composição (1947), não incluía, em suas paisagens solares e desérticas, o Sertão e a Zona da Mata do Nordeste evocado por aqueles autores. Já em Os três mal-amados, de 1943, reconhecia, por meio do monólogo "devorador" de Joaquim, essa ausência:

$\mathrm{O}$ amor comeu meu Estado e minha cidade. Drenou a água morta dos mangues, aboliu a maré. Comeu os mangues crespos e de folhas duras, comeu o verde ácido das plantas de cana cobrindo os morros regulares, cortados pelas barreiras vermelhas, pelo trenzinho preto, pelas chaminés. Comeu o cheiro de cana cortada e o cheiro de maresia. Comeu até essas coisas de que eu desesperava por não saber falar delas em verso. (Melo Neto, 1997a, p.26)

$\mathrm{Na}$ tentativa de descrição, reconhecemos o cenário de mais de um romance de José Lins do Rego, que no máximo poderia ser expurgado e logo descartado na fala prosaica de Joaquim, interrompida pelo silêncio. Se não fosse mais um 
romance na esteira de Zé Lins e companhia, a poesia parece que não daria conta de todo um mundo que fora tão bem representado, inclusive em ensaios.

É justamente fora do país, na Espanha, que Cabral retornou à sua região. Motivado por ideias marxistas e pela necessidade de denúncia social na obra de arte, mas sem prejuízo da sua dimensão estética, escreveu seu primeiro poema centrado na paisagem e no homem nordestino, O cão sem plumas (1951), metáfora para o Rio Capibaribe de Pernambuco. Além disso, para cumprir o ideal de comunicação com o público, a partir de uma linguagem mais prosaica, as obras seguintes - O rio (1954) e Morte e vida Severina (1954-1955) -, baseadas em elementos da poesia medieval espanhola e da literatura popular nordestina, fincam a terra natal na poesia cabralina.

$\mathrm{Na}$ própria Espanha, a tradição literária havia sido recuperada pelos autores da Geração de 98, denominação que alude à derrota vexatória na guerra contra os Estados Unidos, perdendo suas últimas colônias. Agrupava escritores como Miguel de Unamuno, Antonio Machado, Azorín, entre outros, os quais se voltaram à região de Castela para supostamente encontrar uma explicação para os males e as esperanças de toda uma nação. A mensagem de resistência e de luta desses autores calou fundo em outro nordestino, um José Lins que, embora não tenha visto o desastre de uma guerra obrigar um país a se ver atrasado, testemunhou a decadência dos grandes senhores de engenho que deixava ver uma população pobre e explorada. No texto “Espanha, sempre Espanha”, José Lins do Rego (1954, p.44-5) recupera os valores da Geração de 98, os quais também norteavam a retomada social e prosaica da poesia cabralina:

Em 1912 achava Azorín, com sua maravilhosa claridade de espírito, que para a decadência trágica de Espanha haviam concorrido as guerras, a aversão ao trabalho, o abandono da terra e, sobretudo, a falta de curiosidade intelectual. [...]

Para o espanhol, que, em 1912, assistia aterrado ao fim da pátria, escapava-lhe toda preocupação de análise ou de exame de consciência. [...] Verificou-se que Espanha continuava bem viva, bem disposta à saúde. E foi o que fizeram os moços que se voltaram para o passado da Península, com a vontade de vencer o passado, com a vida interior de seus poemas, de seus ensaios, de sua crítica enfim. O próprio Unamuno, filósofo da dor de Castela, soube sofrer as crises de sua gente com uma energia de quem se agarra ao mundo com unhas e dentes.

A geração crítica de Espanha se aprofundou na história para arrancar certezas e domínio sobre o seu destino.

[...] Quase que a Espanha era uma casa mal-assombrada. Por toda parte, sonhos terríveis como imagens de morte punham o povo em pânico. Então os literatos salvaram a Espanha. Os poemas e os romances se voltaram para a terra pobre e para o homem sofrido e triste, e deram força e vida à nação afundada em mágoas.

Com profunda melancolia Azorín confessava: "Reposa el cerebro español como este campo seco y este pueblo grisaceo. No saldrá España de su marasmo secular mientras no haya millares y millares de hombres ávidos de conocer y compreender". 
Não é difícil vislumbrar um paralelo entre a Geração de 98 na Espanha e os romancistas de 30 no Brasil, que no caso de Zé Lins teve um forte estímulo por parte de Gilberto Freyre, profundamente marcado por esses autores iberos, como bem analisa Elide Rugai Bastos (2003) em Gilberto Freyre e o pensamento hispânico. Cabral, por sua vez, faria uma comparação entre a secura da região de Castela - aliás tema recorrente da Geração de 98 - e o sertão nordestino.

Nos depoimentos e nos textos que realizou nesse período, Cabral propõe sugestivamente as relações entre poesia e prosa, e mais de uma vez alude ao romance nordestino de 1930. Na série de artigos que dedicou à poesia da Geração de 45, em 1952, alertou para uma "preferência idealista" em detrimento do "vocábulo prosaico ou pela imagem prosaica", esses promovidos pelos modernistas dos anos 1920; assistia-se a uma "valorização do sublime contra o prosaico, do sobre-real contra o real, do universal contra o nacional ou regional, do inefável contra o tangível" (Melo Neto, 1998, p.83). De acordo com seu "Esboço de panorama", de 1953, a literatura brasileira se fez "poética e abstrata", perdendo espaço a prosa de ficção e o ensaio, tão marcantes nos anos 1930. Até mesmo os remanescentes dessa literatura "objetiva, realista" vinham se modificando ante o predomínio dos "valores poéticos":

Em alguns, deu-se o abandono puro e simples da atividade literária: em outros, o abandono dos temas ou da região que haviam explorado anteriormente, de que haviam falado com toda objetividade, talvez exatamente como uma maneira de fugir à objetividade; em outros, até, a adesão ao novo conceito de literatura que se estava impondo, subjetivo e esteticista, como quer que seja: oposto a tudo o que caracterizou o formidável movimento conhecido como o "romance do nordeste". (Melo Neto, 1998, p.86)

Continuava o cenário presenciado desde os anos de formação de Cabral no Recife: exceção feita ao folhetim O galo de ouro em 1950, Rachel de Queiroz só voltaria à ficção em 1975 com Dôra, Doralina; quanto a José Lins do Rego, abandonou seus engenhos para arribar no Rio de Janeiro com Eurídice (1947), embora encerrasse sua carreira, nesse 1953, com Cangaceiros. Dessa maneira, podemos considerar que em plena década de 1950, O rio e Morte e vida Severina, eminentemente descritivos e narrativos, seriam herdeiros da tradição do romance nordestino na década de 1930.

\section{Construção e espontaneidade}

Passado esse momento mais "prosaico" e de uma poesia mais combativa, em carta de 6 de fevereiro de 1957 a Clarice Lispector, ao comentar a obra da amiga e sua relação com o gênero romance, Cabral refere-se à sua leitura contumaz de José Lins do Rego:

V. sabe perfeitamente que escreve a única prosa de autor brasileiro atual que eu gostaria de escrever. Não digo que V. escreve os únicos romances que eu gostaria de escrever, por dois motivos: a) porque não creio que o romance seja meu meio de expressão etc. etc. (coisas já discutidas com v. há tempos); b) por- 
que sou um sujeito tão envenenado por "construção", montagem, arquitetura literária etc. (coisas que também já conversamos), que forçosamente construiria mais o romance (do que $\mathrm{V}$.): não vai nisso uma crítica, mas o reconhecimento de que distintas coisas buscamos realizar. Etc. etc. Creio que nenhum romance brasileiro reli em minha vida além do Lustre e dos de Zé Lins (este último bastante também por pernambucanismo etc). Ainda aqui, há pouco tempo, voltei a ler pedaços enormes dele. (Lispector, 2002, p.216)

Em um primeiro momento, pode chamar a atenção o apreço de Cabral pela obra de Clarice, a qual teria mais afinidade com a corrente subterrânea ao romance nordestino de apelo social, a do chamado "romance intimista", cultivado, entre outros, por Lucio Cardoso e Cornélio Pena. Mas Cabral parece não se importar com essa divisão rígida do Romance de 30, valorizando autores tão díspares quanto Clarice Lispector e José Lins do Rego. Vale lembrar que, ao longo as décadas de 1950 e 1960 - juntamente com os outros dois grandes escritores do período, a mesma Clarice e Guimarães Rosa -, Cabral tentou ultrapassar ou universalizar a experiência local em sintonia com um apurado e complexo trabalho formal. Quanto a José Lins do Rego, além dos óbvios motivos sentimentais, sua citação na carta a Clarice pode sinalizar uma compensação a esse "formalismo" ao se voltar à espontaneidade do "contador" e do "memorialista". Postura, aliás, retomada bem mais tarde, em A escola de facas (1980), no qual sintomaticamente encontramos um poema intitulado "Menino de engenho", o conhecido romance de estreia de Zé Lins.

E é por meio da oposição entre "formalista" e "espontâneo" que Zé Lins saudara $O$ rio em artigo publicado em $O$ Globo, em 4 de outubro de 1954:

João Cabral de Melo Neto, o poeta hermético de poemas que vão às origens das palavras, verdadeiras pesquisas de laboratório sobre o conteúdo musical do metro, abandona, de súbito, os seus processos e nos aparece como um canto simples, quase que uma narrativa de cantador de feira. Mas aí é que o poeta se revela na sua maior força. Já não intervém na sua poética a obsessão da forma. Já o seu verso não é um jogo de cabeça mais forte do que o coração. Apenas o poeta libertou-se da ciência para ser dos sentimentos. E, assim liberto, veio cantar. (Mamede, 1987, p.300)

O rio sintetiza em seu percurso o "ciclo da cana-de-açúcar" idealizado por Zé Lins: “A história é uma só/ que os rios sabem dizer:/ a história dos engenhos/ com seus fogos a morrer" (Melo Neto, 1997a, p.99).

\section{Um estilo "árido"}

Em um depoimento, Cabral, ao contrário de muitos críticos, não associa todos os escritores nordestinos a um estilo “árido" à maneira do Sertão:

Há dois Nordestes: o do litoral, onde havia Mata e hoje há cana, e o do Sertão. Fui criado em engenho de açúcar. A grande maioria dos meus poemas trata de temas da Zona da Mata. Há poucos poemas sobre o Sertão. Entretanto, a minha forma é mais sertaneja. Não sei por que escrevo árido, se é influência da aridez do Nordeste. Mas, veja que Castro Alves, José Lins do Rego e Gilberto 
Freyre são do Nordeste e não são áridos. Ao contrário de Graciliano Ramos, que é árido também. (Athayde, 1998, p.64)

Seguindo Cabral, podemos rastrear uma verdadeira genealogia do seu estilo "árido" a partir dos romancistas de 30.

A bagaceira (1928), de José Américo de Almeida, considerado o marco do romance do Nordeste na década seguinte, esteve entre as leituras que impressionaram Cabral, como confessa no poema "Díptico: José Américo de Almeida”, de Agrestes (1985):

1.

Muito marcou o adolescente $A$ Bagaceira

o que pareceu tua desarte, vendo em livro o que tinha ouvido, bem antes de ouvir dos Andrades.

Marcou-o, mostrando que escrever é antes de mais nada a aventura de tratar com a linguagem tudo que receia a castiça e eunuca.

2.

Brindo ao mestre de nós todos Brinde nos vindos de certo Brasil noventa onde o Brasil é mais pobre anos não é futuro nem mil:

aos noventa chegaste

fiel ao ser-dizer duro:

sem que se faça um presente

não pode haver um futuro. (Melo Neto, 1997b, p.250-1)

Se desde o início da década de 1920 os paulistas Mário e Oswald combateram uma linguagem academicista e propagaram uma mais afim com o falar dos brasileiros, chegara primeiro a Cabral a lição do romancista paraibano. No prefácio "Antes que me falem", contrário aos ventos vanguardistas vindos do Sul, Américo delimita o cuidado com a linguagem: "A língua nacional tem rr e ss finais... Deve ser utilizada sem os plebeísmos que lhe afeiam a formação. Brasileirismo não é corruptela nem solecismo. A plebe fala errado; mas escrever é disciplinar e construir..." (Almeida, 1968, p.3). Cabral, provavelmente, ficou atento a essas palavras finais.

Logo no primeiro fragmento desse romance seminal que é A bagaceira, “Os salvados", assistimos aos retirantes da seca de 1898: 


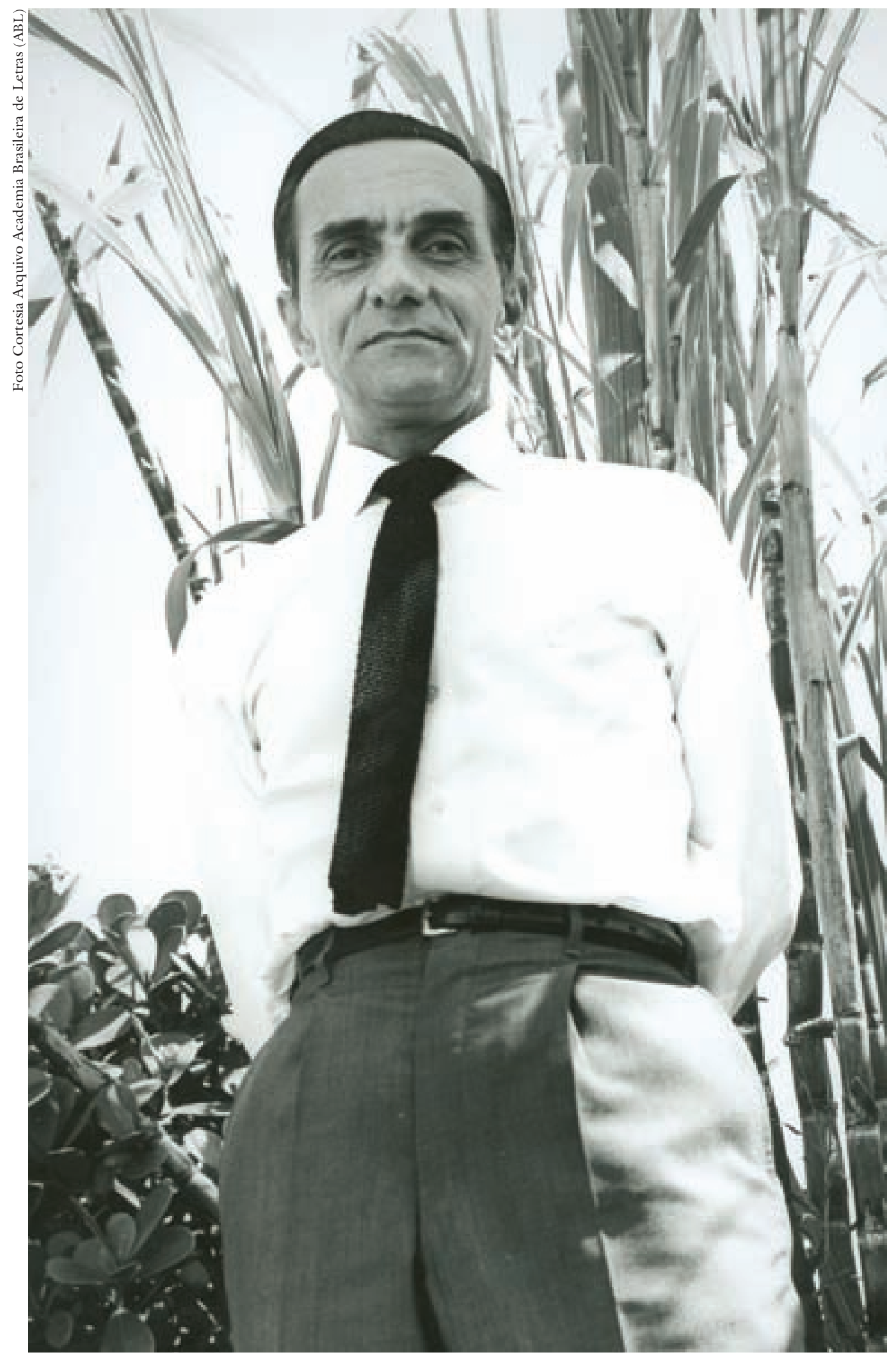

O poeta pernambucano João Cabral de Melo Neto (1920-1999). 
Adelgaçados na magreira cômica, cresciam, como se o vento os levantasse. E os braços afinados desciam-lhes aos joelhos, de mãos abanando.

Vinham escoteiros. Menos os hidrópicos - doentes da alimentação tóxica - com os fardos das barrigas alarmantes.

Não tinham sexo, nem idade, nem condição nenhuma. Eram os retirantes. Nada mais.

Meninotas, com as pregas da súbita velhice, careteavam, torcendo as carinhas decrépitas de ex-voto. Os vaqueiros másculos, como titãs alquebrados, em petição de miséria. Pequenos fazendeiros, no arremesso igualitário, baralhavam-se nesse anônimo aniquilamento.

Mais mortos do que vivos. Vivos, vivíssimos só no olhar. Pupilas do sol da seca. Uns olhos espasmódicos de pânico, assombrados de si próprios. Agônica concentração de vitalidade faiscante. (Almeida, 1968, p.5)

A hesitação entre a grandiloquência de muitos naturalistas de fin de siècle e a "aridez" dos modernos é notória. Posteriormente, em 1969, quando José Américo de Almeida recebeu João Cabral de Melo Neto na Academia Brasileira de Letras, viu com agudeza em seu discurso o poeta que teve nele próprio um dos seus primeiros estímulos e um dos mais altos seguidores: "A técnica despojase do velho formalismo: é resseca e econômica, sem faltar movimento. [...] A estrutura, livre de submissões, escoimada de caturrices vetustas, é culta e pura. [...] O poeta [...] usa a terminologia corrente, cada vocábulo com seu compromisso de traduzir uma verdade..." (Mamede, 1987, p.367-8).

A descoberta de um estilo “árido” em José Américo de Almeida depurouse ao máximo, no âmbito nordestino, com Graciliano Ramos. No poema "A palo seco", de Quaderna (1956-1959), Cabral (1997a, p.234-5) associou a economia de recursos do cante flamenco com um nome que por si só já traduziria uma busca constante por concisão e objetividade:

A palo seco existem

situações e objetos:

Graciliano Ramos,

desenho de arquiteto

as paredes caiadas,

a elegância dos pregos,

a cidade de Córdoba,

o arame dos insetos.

Na coletânea seguinte, Serial (1959-1961), o signo “Graciliano Ramos” retorna; a identificação é tamanha, que o poeta toma emprestada a voz do romancista:

Falo somente com o que falo:

com as mesmas vinte palavras 
girando ao redor do sol

que as limpa do que não é faca:

de toda uma crosta viscosa, resto de janta abaianada, que fica na lâmina e cega seu gosto da cicatriz clara.

Falo somente do que falo: do seco e de suas paisagens, Nordestes, debaixo de um sol ali do mais quente vinagre:

que reduz tudo ao espinhaço, cresta o simplesmente folhagem, folha prolixa, folharada, onde possa esconder-se a fraude.

Falo somente por quem falo: por quem existe nesses climas condicionados pelo sol, pelo gavião e outras rapinas:

e onde estão os solos inertes de tantas condições caatinga em que só cabe cultivar o que é sinônimo da míngua.

Falo somente para quem falo: quem padece sono de morto e precisa um despertador acre, como o sol sobre o olho:

que é quando o sol é estridente, a contrapelo, imperioso, e bate nas pálpebras como se bate numa porta a socos. (Melo Neto, 1997a, p.302-3) 
Como em vários momentos, Cabral "fala" da obra ou atuação do outro para "falar" de si mesmo. As quatro partes do poema refletem os intensos contatos entre as propostas do Romance de 30 e a poesia cabralina voltada para o Nordeste. A partir de uma forma escassa e contundente, ambos procuram denunciar uma terra e um homem duramente castigados pela seca.

Cabral, à maneira de seus poemas divididos em duas ou mais partes, a contrastarem diversos aspectos de um mesmo objeto ou tema, sintoniza-se tanto com esse estilo "árido" de Graciliano, quanto com a procedência da Zona da Mata de Zé Lins. Porém, apenas um trabalho mais detido pode confirmar essa impressão "geográfica" e "estilística", ao detectar possíveis procedimentos da prosa de Graciliano ou Zé Lins na poesia de Cabral, assim como imagens de outros romancistas nordestinos.

\section{Notas}

1 João Miguel (1932), Caminho de pedras (1937) e Astrês Marias (1939).

2 Menino de engenho (1932), Doidinho (1933), Bangüe (1934), O moloque Ricardo (1935) e Usina (1936).

Referências bibliográficas

ALMEIDA, J. A. de. A bagaceira. 10.ed. Rio de Janeiro: José Olympio, 1968.

ATHAYDE, F. de. (Org.) Idéias fixas de João Cabral de Melo Neto. Rio de Janeiro: Nova Fronteira; Mogi das Cruzes: Universidade de Mogi das Cruzes, 1998.

BASTOS, E. R. Gilberto Freyre e o pensamento hispânico: entre Dom Quixote e Alonso el Bueno. Bauru: Edusc, 2003.

LISPECTOR, C. Correspondências. Ed. Teresa Montero. Rio de Janeiro: Rocco, 2002.

MAMEDE, Z. Civil geometria: bibliografia crítica, analítica e anotada de João Cabral de Melo Neto, 1942-1982. São Paulo: Nobel, 1987.

MELO NETO, J. C. de. Serial e antes. Rio de Janeiro: Nova Fronteira, 1997a. A educação pela pedra e depois. Rio de Janeiro: Nova Fronteira, 1997b. . Prosa. Rio de Janeiro: Nova Fronteira, 1998.

REGO, J. L. do. A casa e o homem. Rio de Janeiro: Organizações Simões, 1954.

RESUMO - O artigo analisa a retomada da tradição do romance nordestino da década de 1930 na poesia de João Cabral de Melo Neto, destacando sua aproximação com a obra de José Américo de Almeida, Graciliano Ramos e José Lins do Rego.

PALAVRAS-CHAVE: João Cabral de Melo Neto, Nordeste, Romance de 30. 
ABSTRACT - This article analyses the review of the Northwest Brazil novel tradition in thirties in the Joao Cabral de Melo Neto's poetry and his relationship with the José de Américo de Almeida, Graciliano Ramos and José Lins do Rego's works.

KErWORDS: João Cabral de Melo Neto, Northwest of Brazil, Novel thirties.

Ricardo Souza de Carvalho é professor de Literatura Brasileira do Departamento de Letras Clássicas e Vernáculas da FFLCH-USP. Publicou, entre outros artigos, "O cavalo de todas as cores: uma revista editada por João Cabral de Melo Neto" (Revista USP, n.73, 2007) e "La Revista Americana (1909-1919) y la integración intelectual en Latinoamérica” (Revista Iberoamericana, n.209-210, 2004). @- risocarvalho@hotmail.com Recebido em 21.9.2007 e aceito em 2.4.2008. 